\title{
Editorial
}

\section{Sustainable Consumer Behaviour: A Collection of Empirical Studies}

\author{
Gerrit Antonides \\ Urban Economics, Wageningen University \& Research, P.O. Box 8130, 6700 EW Wageningen, The Netherlands; \\ gerrit.antonides@wur.nl
}

Received: 18 September 2017; Accepted: 19 September 2017; Published: 21 September 2017

\begin{abstract}
We summarise the contributions in this special issue on sustainable consumer behaviour and place them in perspective. Several studies focus on macro- and meso-issues, and others on micro-issues of consumer behaviour. The studies employ a variety of methods, including surveys, field experiments, eye tracking, scale development, and contingent valuation. The 12 contributions from authors of 13 different countries show the wide and varied application of consumer research focused on sustainability issues.
\end{abstract}

Keywords: eco-behaviour; social dilemma; segmentation; food; travel

\section{Introduction}

The solution to sustainability issues is often considered as being driven by product innovation. If products and services would become environmentally-friendly, sustainability would no longer be an issue. However, there are several problems with this view. For example, environmental friendliness often requires high levels of investment, political support, consumer acceptance, and willingness to pay. Given the high number of product innovation failures, the study of consumer behaviour seems vital in guiding the direction of product design and policy measures aimed at stimulating sustainable behaviour. Arguments like this underlie the motivation for this special issue on consumer behaviour.

Sustainable consumer behaviour may be approached from different perspectives, including-among others-the policy maker's view, the marketing view, the consumer interest focus, and the ethical focus. Consumer research also applies a variety of different research methodologies. The different angles and methodologies are reflected in the contributions to this special issue, but all of them are empirical, thus providing "flesh to the bones" of consumer theories.

Consumer behaviour research is often an amalgamation of theories and different methodologies, each contributing different pieces to the entire puzzle which is the explanation of consumer behaviour. In this respect, consumer behaviour research is different from economic analysis, which is usually derived from a set of assumptions and leads to a normative framework of consumer decision making. In contrast, students of consumer behaviour often complain about the myriad theories and insights that exist in the field. My answer to their complaints is that consumer behaviour is too complex to be described by one overarching theory, and consumer behaviour researchers should strike a balance between the generality of theory and the set of behaviours that it should explain. For example, we have contributions dealing with social dilemma theory and collective effort, providing some explanation for a particular aspect of sustainable behaviour-namely, social influence. However, such research cannot explain consumer decision making in making trade-offs between price and sustainability, so other research contributions cover this type of decision making. However, decision making research often starts at a higher level of abstraction than the elementary process of perception, for which still other types of research are needed. This special issue reflects this aim for balance. 


\section{Macro and Meso Views on Sustainable Consumer Behaviour}

The Effect of Elite Polarization [1] combines data from EU inhabitants in the Eurobarometer Survey and from the comparative Manifestos Project, including political party positions regarding environmental protection. It appears that the EU citizens' perceived threat of climate change and personal actions to reduce climate change are both negatively influenced by the diversity in political parties' positions regarding the environment. Additionally, perceived threat tends to be positively related to reported personal actions to reduce climate change. The total effect of political party positions thus seems greater than hitherto expected.

In Does Nationality Matter in Eco-Behaviour? [2], Italian and Chinese samples are compared on eco-awareness, eco-behaviour, green opinion, a number of different personal values, and a measure of regulatory focus. Although nationality has no significant effect on eco-behaviour in the extended model, a stepwise analysis shows that in addition to the universalism value and regulatory focus, Chinese rather than Italian citizens are more likely to adopt eco-behaviour, despite the fact that Italians are more eco-aware than the Chinese.

Sustainable Consumption Dilemmas [3] considers both the social dilemma and moral dilemma aspects of sustainable consumer behaviour with respect to meat consumption. Unlike most studies, real behaviour has been studied in a large-scale field experiment in which participants received credit which was large enough to cover the extra costs of buying organic meat as compared with conventional meat. Participants in groups of different sizes then voted either in favour of an obligation to use the group members' credit only for buying organic meat, or in favour of freedom to use the credit for organic or non-organic meat. Although the share of votes in favour of the obligation was quite high (around 50\%), group size differences were not significantly related to the votes, thus rejecting the social dilemma hypothesis. On the other hand, $76 \%$ of the participants were willing to buy organic meat if a certain number of other group members would do the same, thus pointing to a moral dilemma based on a trade-off between individual costs and collective gains.

Collective efforts in reducing waste were studied in Keep on Rockin' in a (Plastic-)Free World: Collective Efficacy and Pro-Environmental Intentions as a Function of Task Difficulty [4]. In an innovative experiment, 6000 cards were given out to citizens across Germany. On each of the cards a specific challenge was displayed, which was either easy (I carried my groceries home in either a fabric bag, a backpack, or a basket), moderate (While shopping, I bought all fruits and vegetables without plastic wrapping, and I consequently brought them home in either a fabric bag, a backpack, of a basket), or difficult (I did my entire shopping entirely without plastic. This means that I neither bought plastic bags of any sort nor did I buy any other sort of plastic wrapping). After performing the challenge, participants then completed a questionnaire on the web, including questions about collective efficacy, self-efficacy, and trust in collective performance, among others. As predicted, moderate challenges resulted in higher collective efficacy, whereas task difficulty did not affect self-efficacy. The experiment shows that trust in collective performance of environmental behaviour depends on task difficulty, which may be useful for the way in which collective actions can be stimulated.

The first two papers in this section show that both the political climate and nationality are significant factors in increasing the level of eco-behaviour. However, the actual psychological processes behind these factors need to be understood better in future research. The third paper points to the significance of social influence on consumption without restricting other people's freedom of choice. The fourth paper shows that collective efforts may depend on task difficulty.

\section{Micro Views on Sustainable Consumer Behaviour}

\subsection{Typology and Segmentation Studies}

A qualitative study, Making Sense of Sustainability: A Practice Theories Approach to Buying Food [5], has explored different typologies of sustainable food consumers. The typology is based on several criteria, one of which is the people and motivations involved in acquiring the practice of buying 
sustainable food. These might include, for example, parents focusing on healthy diets, friends focusing on environmental concern, or exogenous factors such as living abroad or enrolment in environmental associations. Another criterion concerns the way consumers are engaged in sustainable consumption - for example, by focusing on health, quality of food, or ethics involved in sustainable purchases. The third criterion involves the degree of commitment of sustainable consumers, in knowing, questioning, or pushing their limits. The fourth criterion relates sustainable food consumption to other sustainable consumption, including recycling, saving energy, transportation, etc. The latter criterion seems to be associated with the issue of spillover effects. Since this study is based on a small sample, the typology needs to be confirmed in larger samples in order to be considered in policy making.

Attribute Segmentation and Communication Effects on Healthy and Sustainable Consumer Diet Intentions [6] combines a segmentation of Dutch food consumers with an experiment on communicating dietary guidelines for healthy and/or sustainable food consumption. The segmentation was based on the importance of a range of sustainability aspects, price, taste, and healthiness, and resulted in three segments: pro-self, average, and conscious consumers. Communication concerning sustainability and healthiness of diets was presented to each of four randomly selected parts of the sample in a $2 \times 2$ (health arguments vs. sustainability arguments) full-factorial between-subjects design. Pro-self and average consumers were thinking most about sustainability due to communication that combined health and sustainability benefits, although no changes in dietary intentions were found in these segments. The combined health and sustainability communication increased the intention to reduce meat consumption for sustainable conscious consumers most. Apparently, communication concerning sustainability and health had differential effects on different consumer segments.

In Market Opportunities for Animal-Friendly Milk in Different Consumer Segments [7], a segmentation of Flemish milk consumers is reported, based on purchase intention and perceived evaluation of the current state of dairy cattle welfare. Six consumer segments were found, thus reflecting the high differentiation of the Flemish market for milk. The authors observe that milk market supply does not show a similar differentiation. Hence, they propose to focus on enhanced animal welfare in positioning milk products on the market, including access to pasture, freedom of movement, and absence of diseases. In addition, a star (or equivalent) rating system might serve as a means to increase the market share of animal-friendly milk products, and to encourage farmers to invest in cow welfare.

Rather than studying consumer opinions and intentions, An Environmental Perspective on Clothing Consumption: Consumer Segments and Their Behavioural Patterns [8] uses self-reported consumer behaviour as the basis for the segmentation of consumers in four different countries. Based on reported number of clothing items purchased, expenditures, brand, acquisition mode, and sustainable clothing material purchased, five segments were found, ranging from low amount of consumption and purchasing at budget outlets to high-volume consumption and premium outlets. It appears that only the upper two segments, comprising less than $10 \%$ of the total population, bought sustainable apparel significantly more often. Although the authors suggest different interventions to promote sustainable clothing consumption, the opportunities seem to be limited.

Apparently, segmentation can be accomplished in different ways on which different interventions for sustainable consumption can be based. As a tentative conclusion of this section, interventions aimed at changing attitudes and opinions may be more successful than those aimed at changing behaviour directly.

\subsection{Miscellaneous Topics}

Travel behaviour is an important type of consumer behaviour in regard to sustainability. Fostering Sustainable Travel Behaviour: Role of Sustainability Labels and Goal-Directed Behaviour Regarding Touristic Services [9] studies the awareness of eco-labels, and the attractiveness of hotel offerings and the preference for certified tour operators in relation to the presence of eco-labels on the web sites of suppliers. The first study used eye tracking to measure the number of fixations and average fixation 
durations for different stimuli present on the web sites as an indicator of awareness. Clearly, awareness was higher for larger eco-labels than for smaller ones, and was also positively related to attractiveness of the offer. The second study focused on the trustworthiness of sustainability certifications for tour operators, and shows that preference for tour operators was positively influenced by the perceived trustworthiness of certifications. In sum, the research shows that informative labels positively influence consumers' awareness and preferences for sustainable travel.

The second paper on eco-friendly travel choices, Can Social Comparison Feedback Affect Indicators of Eco-Friendly Travel Choice? Insights from Two Online Experiments [10], studies the effect of social comparison feedback on the students' ecological footprint on eco-friendly travel intentions. After calculating the students' ecological footprints and the number of Earths needed if everybody would behave like the participant, they were given information about the number of Earths needed if other students had either higher or lower ecological footprints. Additionally, measures were taken regarding the participants' identification with students at their university as a group. It was found that intentions to travel eco-friendly were positively related to negative comparison feedback, but only when group identification was high. A second study was not able to replicate the significant finding from the first study, thus calling for further research on this issue.

Collaborative Consumption: A Proposed Scale for Measuring the Construct Applied to a Car-Sharing Setting [11] reports on the construction of a car-sharing scale in Brazil. Starting with 29 items, 9 items were removed because of their performance in exploratory factor analyses. The remaining items were included in confirmatory factor analysis, resulting in five factors: socio-environmental consciousness, trust, social identity, convenience, and risks. The subscales showed unidimensionality, reliability, and convergent and discriminant validity. Although the scale development was satisfactory, it has not been tested in an independent sample, and is limited to car sharing only.

Since price if often competing with environmental friendliness, it is important to estimate consumers' willingness to pay (WTP) for environmentally-friendly products. Consumers' Willingness to Pay a Premium for Eco-Labeled LED TVs in Korea: A Contingent Valuation Study [12] assesses WTP for a popular eco-friendly LED TV by using a sophisticated contingent valuation method. The estimated WTP amounts to about $4 \%$ of the price of the TV and is higher for high-income, older, highly-educated, and female consumers with children. Although contingent valuation is not based on actual behaviour, the methodology is directly relevant for suppliers of new eco-friendly products on the consumer market.

The first two papers in this section dealt with the role of information on preferences and behaviour, without focusing on particular segments. The final two papers deal with measurement issues in consumer behaviour (i.e., scale development and WTP measurements). This section touches on the basics of consumer behaviour.

Conflicts of Interest: The author declares no conflicts of interest.

\section{References}

1. Sohlberg, J. The Effect of Elite Polarization: A Comparative Perspective on How Party Elites Influence Attitudes and Behavior on Climate Change in the European Union. Sustainability 2017, 9, 39. Available online: http:/ / www.mdpi.com/2071-1050/9/1/39 (accessed on 28 December 2016). [CrossRef]

2. Bonera, M.; Corvi, E.; Codini, A.P.; Ma, R. Does nationality matter in eco-behaviour? Sustainability $2017,9$. in press.

3. Vringer, K.; Heijden, E.; Soest, D.; Vollebergh, H.; Dietz, F. Sustainable Consumption Dilemmas. Sustainability 2017, 9, 942. Available online: http://www.mdpi.com/2071-1050/9/6/942 (accessed on 3 June 2017). [CrossRef]

4. Reese, G.; Junge, E. Keep on Rockin' in a (Plastic-) Free World: Collective Efficacy and Pro-Environmental Intentions as a Function of Task Difficulty. Sustainability 2017, 9, 200. Available online: http:/ /www.mdpi. com/2071-1050/9/2/200 (accessed on 1 February 2017). [CrossRef] 
5. Brons, A.; Oosterveer, P. Making Sense of Sustainability: A Practice Theories Approach to Buying Food. Sustainability 2017, 9, 467. Available online: http://www.mdpi.com/2071-1050/9/3/467 (accessed on 21 March 2017). [CrossRef]

6. Verain, M.; Sijtsema, S.; Dagevos, H.; Antonides, G. Attribute Segmentation and Communication Effects on Healthy and Sustainable Consumer Diet Intentions. Sustainability 2017, 9, 743. Available online: http: / / www.mdpi.com/2071-1050/9/5/743 (accessed on 4 May 2017). [CrossRef]

7. De Graaf, S.; Vanhonacker, F.; Van Loo, E.; Bijttebier, J.; Lauwers, L.; Tuyttens, F.; Verbeke, W. Market Opportunities for Animal-Friendly Milk in Different Consumer Segments. Sustainability 2016, 8, 1302. Available online: http:/ / www.mdpi.com/2071-1050/8/12/1302 (accessed on 11 December 2016). [CrossRef]

8. Gwozdz, W.; Steensen Nielsen, K.; Müller, T. An Environmental Perspective on Clothing Consumption: Consumer Segments and Their Behavioral Patterns. Sustainability 2017, 9, 762. Available online: http:/ / www.mdpi.com/2071-1050/9/5/762 (accessed on 6 May 2017). [CrossRef]

9. Penz, E.; Hofmann, E.; Hartl, B. Fostering Sustainable Travel Behavior: Role of Sustainability Labels and Goal-Directed Behavior Regarding Touristic Services. Sustainability 2017, 9, 1056. Available online: http:/ / www.mdpi.com/2071-1050/9/6/1056 (accessed on 18 June 2017). [CrossRef]

10. Doran, R.; Hanss, D.; Øgaard, T. Can Social Comparison Feedback Affect Indicators of Eco-Friendly Travel Choices? Insights from Two Online Experiments. Sustainability 2017, 9, 196. Available online: http:/ / www.mdpi.com/2071-1050/9/2/196 (accessed on 29 January 2017). [CrossRef]

11. Dall Pizzol, H.; Ordovás de Almeida, S.; do Couto Soares, M. Collaborative Consumption: A Proposed Scale for Measuring the Construct Applied to a Carsharing Setting. Sustainability 2017, 9, 703. Available online: http:/ / www.mdpi.com/2071-1050/9/5/703 (accessed on 28 April 2017). [CrossRef]

12. Min, S.; Lim, S.; Yoo, S. Consumers' Willingness to Pay a Premium for Eco-Labeled LED TVs in Korea: A Contingent Valuation Study. Sustainability 2017, 9, 814. Available online: http:/ /www.mdpi.com/20711050/9/5/814 (accessed on 13 May 2017). [CrossRef]

(C) 2017 by the author. Licensee MDPI, Basel, Switzerland. This article is an open access article distributed under the terms and conditions of the Creative Commons Attribution (CC BY) license (http:/ / creativecommons.org/licenses/by/4.0/). 